\title{
Using Linear Regression to Identify Critical Demographic Variables Affecting Patient Safety Culture From Viewpoints of Physicians and Nurses
}

\author{
Chih-Yi Chi' ${ }^{1}$ Hsin-Hung Wu ${ }^{1 *}$, Chih-Hsuan Huang², Yii-Ching Lee ${ }^{3,4,5}$ \\ ${ }^{1}$ Department of Business Administration, National Changhua University of Education, Changhua City, Taiwan \\ ${ }^{2}$ School of Business Administration, Hubei University of Economics, Wuhan City, People's Republic of China \\ ${ }^{3}$ Department of Health Business Administration, Hung Kuang University, Taichung City, Taiwan \\ ${ }^{4}$ School of Health Policy and Management, Chung Shan Medical University, Taichung City, Taiwan \\ ${ }^{5}$ Quality Management Center, Shanghai Changtai Medical Technology Co. Ltd., Shanghai, People's Republic of China
}

*Corresponding Author: Hsin-Hung Wu, Ph.D., Professor, Department of Business Administration, National Changhua University of Education, No. 2 Shida Road, Changhua City, Taiwan. Tel/Fax: +886-4-7232105 ext. 7412/+886-47211292,Email: hhwu@cc.ncue.edu.tw

Received April 8, 2017; Accepted May 6, 2017; Online Published May 31, 2017

\begin{abstract}
Background: The issues of patient safety and healthcare quality have become increasingly important around the world since the 1990s. Many hospitals manage to reduce the number of adverse events (AEs) that can threaten patient safety in healthcare organizations. Assessing the existing patient safety culture gives hospital management a clear vision of an organization's strengths and weaknesses. The Safety Attitudes Questionnaire, with its good psychometric properties and great internal consistency, has been used extensively to assess the patient safety culture in healthcare organizations.

Objective: Physicians and nurses form the core staff of each organization. With different demographic variables, they might perceive patient safety culture differently. This study purposed to identify critical demographic variables from the viewpoints of physicians and nurses that significantly influence the patient safety culture in a regional teaching hospital in Taiwan.

Methods: Linear regression with forward selection was employed in this study to focus on all physicians and nurses using results of a 2015 internal survey in the case hospital. Ten demographic variables were the independent variables, and seven dimensions of the Chinese version of the Safety Attitudes Questionnaire were dependent variables.

Results: Four out of 10 demographic variables had significant impacts on 6 out of 7 dimensions (with the exception of emotional exhaustion) from the Safety Attitudes Questionnaire. "Supervisor/manager" and "experience in position" followed by "age" were viewed by physicians and nurses as the most critical variables affecting the patient safety culture in this regional teaching hospital in Taiwan.

Conclusion: Assessing an organization's current patient safety culture provides a significant value to improving patient safety. This study revealed that "supervisor/manager" and "experience in position" are the 2 most important demographic variables influencing the patient safety culture. Hospital management should take heed of the suggestions of staff members regarding these characteristics to continuously enhance their patient safety culture.

Keywords: Patient Safety, Linear Regression, Physicians, Nurses
\end{abstract}

\section{Background}

The issues of patient safety and healthcare quality have become increasingly important across the world since the 1990s. Many hospitals manage to reduce the occurrence of adverse events (AEs) which are common in healthcare organizations. AEs due to a defective system or human negligence are enormous threats to patient safety. Previous studies in several countries have shown that approximately half of all AEs are considered preventable. ${ }^{1}$ Some healthcare initiatives or policies have been implemented to enhance the quality of healthcare. The National Patient
Safety Agency in England advocated that healthcare organizations establish a "patient safety culture" which focuses on lessening and preventing harm to patients during the delivery of healthcare. ${ }^{2,3}$

A high level of patient safety results in positive assessments of care by patients. ${ }^{4,5}$ Patient safety culture is defined as "the values shared among organization members about what is important, their beliefs about how things operate in the organization, and the interaction of these with work unit and organizational structures and systems, which together produce behavioral norms in the organization

Copyright $(C) 2017$ The Hospital Practices and Research. This is an open-access article distributed under the terms of the Creative Commons Attribution License (http://creativecommons.org/licenses/by/4.0), which permits unrestricted use, distribution, and reproduction in any medium, provided the original work is properly cited. 
that promote safety." ${ }^{\prime \prime}$ International institutions such as the Institute of Medicine (IOM) and the Joint Commission are encouraging healthcare organizations to assess patient safety and reinforce medical quality through safety culture surveys. Assessing the existing patient safety culture allows management to have a clear vision of an organization's strengths and weaknesses.

Various measures have been created for gauging a patient safety culture. The Safety Attitudes Questionnaire (SAQ), developed by Sexton et al, possesses good psychometric properties and great internal consistency for healthcare workers in many settings. ${ }^{7-9}$ The SAQ was derived from the Flight Management Attitudes Questionnaire and retained $25 \%$ of it.
The SAQ has been validated in different languages and is recommended as an effective tool for use in patient safety assessment. $^{7,9-15}$ The Joint Commission of Taiwan (JCT) developed the Chinese version of the SAQ (SAQ-C) using forward and backward translation. The intelligibility and item applicability of the questionnaire was confirmed by an expert panel..$^{15}$ JCT modified the original questionnaire from six dimensions and 30 items to nine dimensions and 41 items. The 3 added dimensions (hospital management support for patient safety, teamwork across hospital units, and hospital handoffs and transitions) were integrated into the questionnaire. The SAQ-C current in 2014 retained 6 dimensions of the original SAQ and combined 2 new aspects, "emotional exhaustion" and "work-life balance",

Table 1. Chinese Version of the 2014 Safety Attitudes Questionnaire

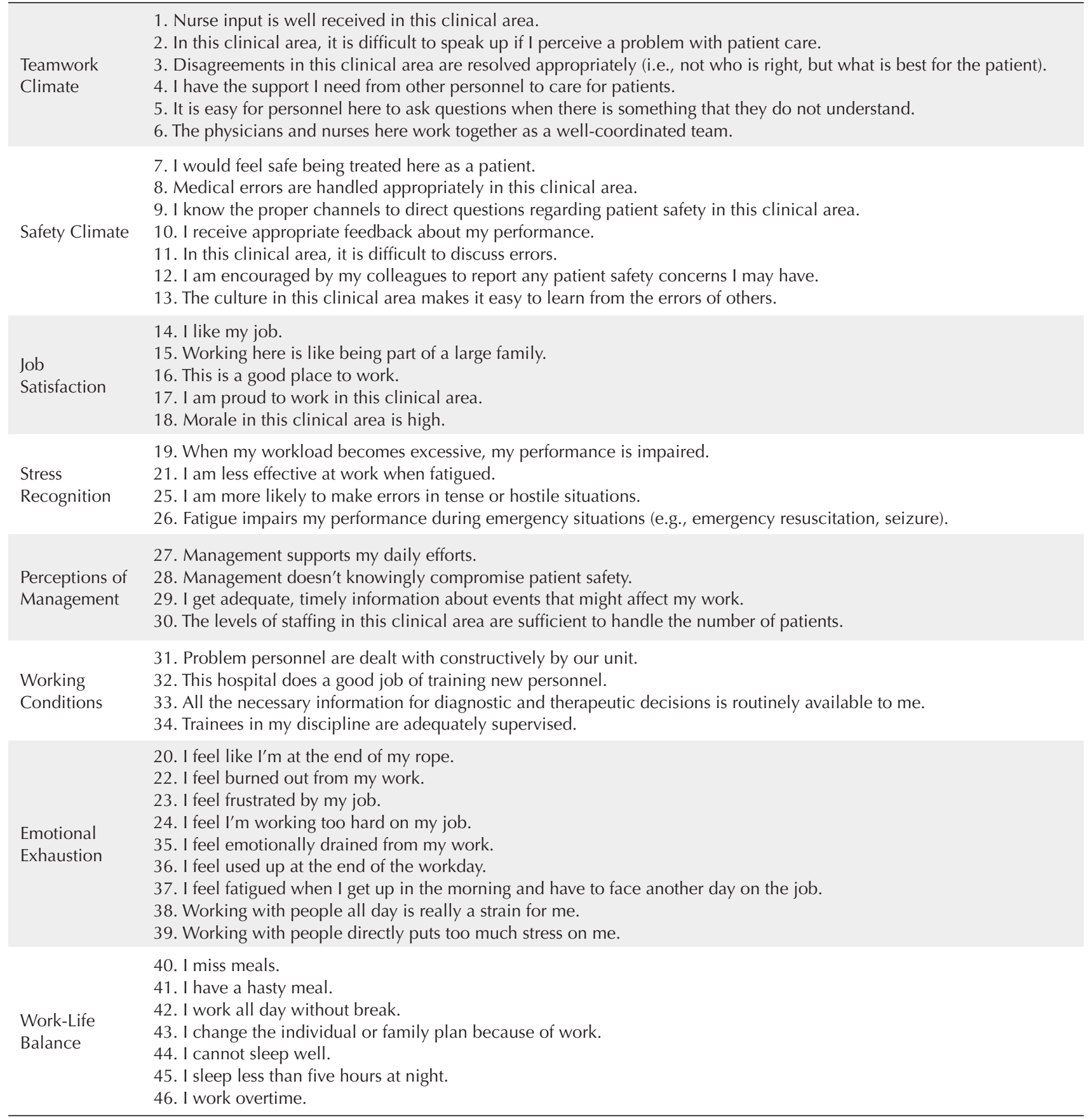


with nine and seven questions, respectively. The latest Chinese version is provided in Table $1 .^{16}$

Relevant research revealed that having different demographic information will lead to different perceptions of patient safety among healthcare providers., ${ }^{2,17,18}$ A study by Kim et al verified that nurses on the front line have more problems with patient safety than those who are older or who work in management positions. ${ }^{19}$ Physicians and nurses form the core staff of each healthcare organization. ${ }^{17}$

\section{Objective}

They are the front line healthcare providers and have contact with patients at a high frequency. It would be of interest to observe how physicians and nurses with different demographic information perceive the patient safety culture. Therefore, this study aimed to identify the crucial demographic variables viewed by physicians and nurses as significantly influencing the patient safety culture in a regional teaching hospital in Taiwan.

\section{Methods}

This research was conducted in 2015 in a regional teaching hospital located in Taichung City, Taiwan. The studied hospital has all the major medical specialties and services and can admit approximately 700 patients. All the physicians and nurses in this hospital were invited to take part in the current study. After removing the invalid parentheses, the valid number of participants in this study was 376 , comprising 42 physicians and 334 nurses. Data was collected internally in this case hospital through the 2014 SAQ-C from JCT which included 46 items that examine medical staff members' attitudes toward eight dimensions, i.e. teamwork climate, safety climate, job satisfaction, stress recognition, perceptions of management, working conditions, emotional exhaustion, and work-life balance. A 5 -point Likert scale ranging from $1=$ strongly disagree to 5 $=$ strongly agree was used for responses for all dimensions except "work-life balance," which used a 4-point scale to measure the frequency per week. Because of its different scale, the analysis of "work-life balance" was excluded from this study. Unlike the other professional groups, physicians and nurses were asked to answer all question items. The demographics of gender, age, supervisor/manager, job position, job status, experience in organization, experience in position, education, and direct patient contact were taken into account for analyses.

Negatively-worded items (Items 2, 11, 20, 22, 23, 24, 35, $36,37,38$, and 39 ) in this questionnaire were reverse scored. Individual questionnaire responses were aggregated by computing the score of the items for each dimension. The demographic variables were independent variables, while the score of each dimension was considered a dependent variable. To predict the dependent variables from predictor variables, this study employed linear regression with forward selection, which started with an empty set and continually added one attribute at a time. At each step, only the attribute which gave the highest performance was added into the selection. The model selection criteria of this technique were tractable and disclosed which independent variable(s) (demographic variable(s)) were critical to a particular dimension..$^{20}$ All statistical analyses were carried out using SPSS software version 18.

Table 2. Demographic Information of the Studied Regional Teaching Hospital

\begin{tabular}{|c|c|c|}
\hline Demographic Variable & No. & Percent \\
\hline \multicolumn{3}{|l|}{ Gender } \\
\hline 1. Male & 57 & 15.2 \\
\hline 2. Female & 319 & 84.8 \\
\hline \multicolumn{3}{|l|}{ Age } \\
\hline 1. Less than 20 years old & 8 & 2.1 \\
\hline 2. 21-30 years old & 144 & 38.3 \\
\hline 3. 31-40 years old & 135 & 35.9 \\
\hline 4. 41-50 years old & 71 & 18.9 \\
\hline 5. 51-60 years old & 17 & 4.5 \\
\hline 6. 61 years old and above & 1 & 0.3 \\
\hline \multicolumn{3}{|l|}{ Supervisor/Manager } \\
\hline 1. Yes & 39 & 10.4 \\
\hline 2. No & 337 & 89.6 \\
\hline \multicolumn{3}{|c|}{ Respondents reporting events in the past 12 months } \\
\hline 1. No & 231 & 61.4 \\
\hline 2. $1-5$ & 127 & 33.8 \\
\hline 3. $6-10$ & 16 & 4.3 \\
\hline 4. $11-15$ & 2 & 0.5 \\
\hline 5. More than 16 & 0 & 0.0 \\
\hline \multicolumn{3}{|l|}{ Job Position } \\
\hline 1. Physician & 42 & 11.2 \\
\hline 2. Nurse & 334 & 88.8 \\
\hline \multicolumn{3}{|l|}{ Job Status } \\
\hline 1. Full Time & 343 & 91.2 \\
\hline 2. Contract & 13 & 3.5 \\
\hline 3. Part Time & 6 & 1.6 \\
\hline 4. Agency & 14 & 3.7 \\
\hline \multicolumn{3}{|l|}{ Experience in Organization } \\
\hline 1. Less than 6 months & 59 & 15.7 \\
\hline 2. 6 to 11 months & 10 & 2.7 \\
\hline 3. 1 to 2 years & 60 & 16.0 \\
\hline 4. 3 to 4 years & 50 & 13.3 \\
\hline 5. 5 to 10 years & 89 & 23.7 \\
\hline 6. 11 to 20 years & 96 & 25.5 \\
\hline 7. 21 years or more & 12 & 3.2 \\
\hline \multicolumn{3}{|l|}{ Experience in Position } \\
\hline 1. Less than 6 months & 67 & 17.8 \\
\hline 2. 6 to 11 months & 9 & 2.4 \\
\hline 3. 1 to 2 years & 68 & 18.1 \\
\hline 4. 3 to 4 years & 58 & 15.4 \\
\hline 5. 5 to 10 years & 100 & 26.6 \\
\hline 6. 11 to 20 years & 68 & 18.1 \\
\hline 7. 21 years or more & 6 & 1.6 \\
\hline \multicolumn{3}{|l|}{ Education } \\
\hline 1. Junior High School or less & 0 & 0.0 \\
\hline 2. Senior High School & 1 & 0.3 \\
\hline 3. College/University & 351 & 93.4 \\
\hline 4. Graduate School or more & 24 & 6.4 \\
\hline \multicolumn{3}{|l|}{ Direct Patient Contact } \\
\hline 1. None & 10 & 2.7 \\
\hline 2. Rarely & 23 & 6.1 \\
\hline 3. Very Often & 343 & 91.2 \\
\hline
\end{tabular}




\section{Results}

Descriptive statistical analyses of respondents' demographic information presenting frequencies and percentages are depicted in Table 2 . Women represented $84.8 \%$ of all the respondents. A total of $35.9 \%$ of respondents were within the age range of 31 to 40 years, while $38.3 \%$ of respondents were 21 to 30 years old. Most of them were not supervisors or managers (89.6\%). During the 12 months preceding this study, more than half of them did not report any event (61.4\%), and a third (33.8\%) reported 1-5 events. A total of $91.2 \%$ of sample respondents had full-time jobs in this hospital. In addition, $25.5 \%$ of respondents had 11 to 20 years of experience in the organization, while $26.6 \%$ of them had 5 to 10 years of experience in their positions. The majority of respondents indicated that their work required them to have direct contact with patients $(91.2 \%)$.

The results of the linear regression with forward selection are presented in Table 3 with $\alpha=0.05$. The adjusted $\mathrm{R}$-square values range from 0.048 to 0.138 . Teamwork climate was negatively influenced by "supervisor/manager" and "experience in position," indicating that physicians and nurses who are not in charge are less satisfied, and physicians and nurses who have much more experience in their positions tend to be less satisfied as well. "Supervisor/ manager" and "experience in position" had negatively impacts on the safety climate. That is, physicians and nurses who are not in charge and who have more experience in their positions are less satisfied.

"Supervisor/manager", "age", and "experience in position" are the 3 critical demographic variables affecting job satisfaction. Physicians and nurses who are in charge, elderly, or less experienced in their positions tend to have higher job satisfaction. Stress recognition is impacted by job position and supervisor/manager. Specifically, nurses tend to have less satisfaction in stress recognition.

"Supervisor/manager" and "experience in position" are the 2 essential demographic variables that negatively influence perceptions of management. Physicians and nurses who are not supervisors/managers and/or have much experience in their positions tend to have less satisfaction in perceptions of management. The dimension of "working conditions" was impacted by "supervisor/ manager", "experience in organization", and "age". Physicians and nurses who have much experience in the organization feel less satisfied. In contrast, employees who are elderly are more satisfied with their working conditions. Finally, the linear regression model could not be established between the dimension of "emotional exhaustion" and ten demographic variables. By further examining the correlation between "emotional exhaustion" and the demographic variables, the $P$ values ranging from 0.067 to 0.976 indicate that there is no correlation between them if $\alpha$ is set to 0.05 .

The correlation of seven dimensions and critical demographic variables is shown in Table 4. In summary, physicians and nurses who are not supervisors/managers feel less satisfied with the teamwork climate, safety climate, job satisfaction, stress recognition, perceptions of management, and working conditions. Employees who have much experience in their positions tend to be less satisfied with the teamwork climate, safety climate, job satisfaction, and perceptions of management. In addition, employees who have much experience in an organization are less satisfied with the working conditions. On the other hand, physicians have less stress than nurses. Finally, older employees tend to have a high satisfaction with their jobs and working conditions.

The coefficients of most explanatory variables were negative, clarifying that the respondents who were supervisors/managers and who had much experience in their positions had the greatest effect on the patient safety culture in this investigation. Healthcare workers who were supervisors/managers in this hospital indicated a higher level of satisfaction on the SAQ-C with the teamwork climate, safety climate, job satisfaction, stress recognition, perceptions of management, and working conditions. Healthcare workers with less experience in their positions in this hospital were inclined to have better perceptions of the teamwork climate, safety climate, job satisfaction, and perceptions of management. Nevertheless, "age" was the

Table 3. Linear Regression With Forward Selection of 7 Dimensions

\begin{tabular}{llcccc}
\hline & Demographic Variable & Unstandardized Coefficients & Standardized Coefficients & $t$ & $\boldsymbol{P}$ \\
\hline \multirow{2}{*}{ Teamwork climate } & Supervisor/ Manager & -4.170 & -0.289 & -5.702 & 0.000 \\
& Experience in position & -0.319 & -0.126 & -2.479 & 0.0014 \\
Safety climate & Supervisor/ Manager & -5.292 & -0.327 & -6.507 & 0.000 \\
& Experience in position & -0.312 & -0.109 & -2.179 & 0.030 \\
Job satisfaction & Supervisor/ Manager & -3.861 & -0.282 & -7.025 & 0.000 \\
& Age & 1.042 & 0.236 & 5.119 & 0.000 \\
\multirow{3}{*}{ Stress recognition } & Experience in position & -0.508 & -0.213 & -4.646 & 0.000 \\
\multirow{3}{*}{ Perceptions of managemen } & Job position & -1.672 & -0.155 & -3.033 & 0.003 \\
& Supervisor/Manager & -1.614 & -1.45 & -2.834 & 0.005 \\
\cline { 2 - 4 } Working conditions & Supervisor/Manager & -2.805 & -0.296 & -5.934 & 0.000 \\
& Experience in position & -0.390 & -0.234 & -4.698 & 0.000 \\
& Supervisor/Manager & -2.861 & -0.292 & -5.461 & 0.000 \\
& Experience in position & -0.533 & -0.318 & -5.472 & 0.000 \\
& Age & 0.447 & 0.137 & 2.242 & 0.0026 \\
\hline
\end{tabular}


Table 4. Summary of 7 Dimensions and Critical Demographic Variables

\begin{tabular}{|c|c|c|c|c|c|c|c|}
\hline & $\begin{array}{l}\text { Teamwork } \\
\text { Climate }\end{array}$ & $\begin{array}{l}\text { Safety } \\
\text { Climate }\end{array}$ & $\begin{array}{l}\text { Job } \\
\text { Satisfaction }\end{array}$ & $\begin{array}{l}\text { Stress } \\
\text { Recognition }\end{array}$ & $\begin{array}{l}\text { Perceptions of } \\
\text { Management }\end{array}$ & $\begin{array}{l}\text { Working } \\
\text { Conditions }\end{array}$ & $\begin{array}{l}\text { Emotional } \\
\text { Exhaustion }\end{array}$ \\
\hline Age & & & + & & & + & \\
\hline Supervisor/Manager & - & - & - & - & - & - & \\
\hline Job position & & & & - & & & \\
\hline Experience in organization & & & & & & - & \\
\hline Experience in position & - & - & - & & - & & \\
\hline
\end{tabular}

only positive demographic variable. It is worth mentioning that job position had some bearing on patient safety culture.

\section{Discussion}

This study utilized the SAQ-C to assess the patient safety culture and identify the crucial demographic variables from the viewpoints of 376 physicians and nurses in 2015. Linear regression with forward selection was applied to analyze the data; results indicated that the predictor variable "supervisors/managers" was the most important variable for the respondents in this research.

Employees who serve as supervisors/managers had greater perceptions on all of the dimensions. In other words, the supervisors or managers who are the promoters of establishing a patient safety culture may have increased the outcome of this survey. According to some studies, leaders are the ones who understand current safety issues thoroughly and are able to create a patient safety culture. ${ }^{21,22}$ They have a better comprehension of the patient safety culture than others. Their recognition of the patient safety culture will be changed whether or not the hospital policies are practiced well. The dimensions in SAQ-C are jointly related. The overall performance of the patient safety culture is affected by such recognition. Furthermore, some researchers do validate that leadership is associated with safety outcomes. ${ }^{23}$ A leader can have an immense effect on individual employee behaviors in relation to safety. ${ }^{24}$ Hospital management should make appropriate interventions to enhance a leader's effectiveness in engaging their subordinates' commitment.

The demographic variable "experience in position" demonstrated a negative influence on the teamwork climate, safety climate, job satisfaction, and perceptions of management. Therefore, employees with less experience in their positions had a higher satisfaction with these four dimensions than those with ample experience. These results contrast with those of Khater et al who explored nurses' perceptions of the patient safety culture. ${ }^{25}$ Their study indicated that the higher the number of total years of experience is, the better the nurse's perception of the patent safety culture will be. Comparing the current study with the research conducted by Khater et $\mathrm{al}^{25}$ highlighted some reasons that may have led to the diverse results. First, different measurement tools were used. Instead of the SAQ, Khater et al employed a hospital survey on patient safety culture developed by the Agency for Healthcare Research and Quality (AHRQ). Second, there is disparity in the sample size. Third, the current study surveyed physicians and nurses, while nurses were the only respondents in Khater and colleagues' study.

In the current study, "experience in organization" was shown to have a negative impact on working conditions. Respondents who had less experience in the organization had more satisfaction with the patient safety culture. A research regarding nurses from Korea also showed that nurses with fewer years of work experience at the present hospital held more positive views about the safety culture. ${ }^{19}$

Different age groups revealed diverse perceptions of the patient safety culture. The older healthcare workers in this hospital tended to have a greater patient safety culture. This result was also supported by a research in South Australia. ${ }^{26}$ It can be inferred that older respondents may have a greater possibility of working in a better working environment, which will increase their perceptions of the patient safety culture. Another explanation might be an old ethic from Asian culture. In the Chinese traditional culture, maintaining harmony is always the top priority in the workplace; this tradition may cause staff members to conceal their true thoughts. Apparently, this might not be happening with the younger generation.

It should be noted that job position only influenced stress recognition. That is, physicians had a better recognition of stress than nurses in this teaching hospital. Considering some aspects from the dimension "stress recognition" on the SAQ, it is interesting to note that this dimension differs slightly from the others. The other dimensions inquire about behaviors that are related to other people in the workplace, while stress recognition focuses on respondents themselves, e.g., personal behaviors. When respondents are inclined to approve the items of stress recognition, that demonstrates how stress affects their work performance. Without a doubt, negative emotions will increase the possibility of workplace deviations. Some organizations or companies do not allow personal emotions to be brought to work, especially negative ones. The regulations or organizational culture mentioned above will affect the replies of respondents.

One possible solution to relieving negative emotions for physicians and nurses is to provide for them the mindfulness-based stress reduction program created by Dr. Jon Kabat-Zinn in 1979, building up the "positivity currency" of the staff, or establishing "appreciative inquiry" groups. ${ }^{18}$ The general purpose of this program is to teach staff how to deal with stress, pain, and illness. In addition, when individuals focus on positive attitudes toward interactions, life events, and memories, and express their gratitude, "positivity currency" can be 
printed and stored as assets. That is, maintaining a positive outlook and regularly expressing gratitude are the real values needed for employees to build resilience. Finally, "appreciative inquiry" is a model to cultivate employees in self-determined changes. Praising staff members for their past successful experiences is positive encouragement for employees to enthusiastically enhance resilience and a positive psychology toward negative emotions.

\section{Conclusion}

Many countries are making major efforts to enhance patient safety, and healthcare organizations have been encouraged to assess the existing culture in recent years. Such an assessment would provide significant values for enhancing the perceptions of the patient safety culture. It would give hospital management the clues they need to identify flaws in their hospitals and redesign systems if necessary. The current study revealed that "supervisor/ manager" and "experience in position" followed by "age" are the most important demographic variables influencing the patient safety culture from the viewpoints of physicians and nurses.

Hospital management should heed the advice of staff members regarding these characteristics. Programs can be established for pioneering patient safety and keeping track of the outcomes from a survey based on the SAQ-C once a year to continuously improve the patient safety culture for healthcare organizations. Specific activities such as a mindfulness-based stress reduction program, positivity currency, or appreciative inquiry groups can be applied to teach physicians and nurses how to strengthen resilience and positive psychology toward negative emotions. Finally, the patient safety culture as viewed by the staff should be tracked on a yearly basis to monitor performance trends in order for healthcare organizations to provide a better healthcare environment for their patients.

\section{Authors' Contributions}

All authors contributed equally to this research.

\section{Conflicts of Interest Disclosures}

Hsin-Hung Wu received financial support from the Ministry of Science and Technology in Taiwan with the grant number of MOST 105-2221-E-018-015. For the remaining authors, none were declared.

\section{Ethical Approval}

The clinical trial approval certificate (ethic statement) was approved by Cheng Ching General Hospital in Taichung, Taiwan with protocol number HP150029.

\section{References}

1. Zegers M, de Bruijne MC, Wagner C, et al. Adverse events and potentially preventable deaths in Dutch hospitals: results of a retrospective patient record review study. Qual Saf Health Care. 2009;18(4):297-302. doi:10.1136/qshc.2007.025924.

2. Abdou HA. Saber KM. A baseline assessment of patient safety culture among nurses at student university hospital. World J Med Sci. 2011;6(1):17-26.

3. Yang CC, Wang YS, Chang ST, Guo SE, Huang MF. A study on the leadership behavior, safety culture, and safety performance

\section{Research Highlights}

\section{What Is Already Known?}

Based on a literature review, few studies (maybe none) have used each dimension of the Safety Attitudes Questionnaire as the outcome of linear regression and ten demographic variables as input variables from the viewpoints of physicians and nurses.

\section{What This Study Adds?}

The major contribution of this pilot study is the use of a regional teaching hospital as a case study to show that the relationship between each dimension and ten demographic variables can be established using linear regression with forward selection. In doing so, critical demographic variables that have significant impacts on each dimension were identified. Hospital management in this case hospital can use the results to take actions to improve the patient safety culture. Moreover, the authors believe that this philosophy can be further applied to other healthcare organizations worldwide when the patient safety culture is the focus.

of the healthcare industry. Int J Soc Behav Educ Econ Bus Ind Eng. 2009;3(5):546-553.

4. Nieva VF, Sorra J. Safety culture assessment: a tool for improving patient safety in healthcare organizations. Qual Saf Health Care. 2003;12(suppl 2):17-23.

5. Ulrich B, Kear T. Patient safety and patient safety culture: Foundations of excellent health care delivery. Nephrol Nurs J. 2014;41(5):447-456

6. Singer S. Lin S. Falwell A. Gaba D. Baker L. Relationship of safety climate and safety performance in hospitals. Health Serv Res. 2009;44(2 Pt 1):399-421. doi:10.1111/j.14756773.2008.00918.x

7. Sexton JB, Helmreich RL, Neilands TB, et al. The safety attitudes questionnaire: Psychometric properties, benchmarking data, and emerging research. BMC Health Serv Res. 2009;6:44. doi:10.1186/1472-6963-6-44.

8. Zenere A, Zanolin ME, Negri R, et al. Assessing safety culture in NICU: psychometric properties of the Italian version of safety attitude questionnaire and result implications. J Eval Clin Pract. 2015;22(2):275-282. doi:10.1111/jep.12472.

9. Nguyen G, Gambashidze N, Ilyas SA, Pascu D. Validation of the safety attitudes questionnaire (short form 2006) in Italian in hospitals in the northeast of Italy. BMC Health Serv Res. 2015;15:284. doi:10.1186/s12913-015-0951-8.

10. Deilkås ET, Hofoss D. Psychometric properties of the Norwegian version of the safety attitudes questionnaire $(S A Q)$, generic version (Short Form 2006). BMC Health Serv Res. 2008;8:191.

11. Kaya S, Barsbay S, Karabulut E. The Turkish version of the safety attitudes questionnaire: psychometric properties and baseline data. Qual Saf Health Care. 2010;19(6):572-577. doi:10.1136/qshc.2008.032003.

12. Devriendt E, Van den Heede K, Coussement J, et al. Content validity and internal consistency of the Dutch translation of the safety attitudes questionnaire: An observational study. Int J Nurs Stud. 2012;49:327-337. doi:10.1016/j.jinurstu.2011.10.002.

13. Göras C, Wallentin FY, Nilsson U, Ehrenberg A. Swedish translation and psychometric testing of the safety attitudes questionnaire (operating room version). BMC Health Serv Res. 2013;13:104. doi:10.1186/1472-6963-13-104.

14. Hamdan $\mathrm{H}$. Measuring safety culture in Palestinian neonatal intensive care units using the safety attitudes questionnaire. J Crit Care. 2013;28:886.e7-886.e14.

15. Lee $\mathrm{YC}, \mathrm{Wu} \mathrm{HH}$, Hsieh $\mathrm{WL}$, Weng SJ, Hsieh LP, Huang $\mathrm{CH}$. 
Applying importance-performance analysis to patient safety culture. Int J Health Care Qual Assur. 2015;28(8):826-840. doi:10.1108/IJHCQA-03-2015-0039.

16. Lee $\mathrm{YC}$, Chi $\mathrm{CY}$, Huang $\mathrm{CS}, \mathrm{Wu} \mathrm{HH}$. Identifying critical demographic variables that affect the Chinese version of the safety attitudes questionnaire in a regional teaching hospital in Taiwan. 6th International Conference on Application of Information and Communication Technology and Statistics in Economy and Education (ICAICTSEE - 2016); 2016:FA-04.

17. Lee YC, Weng SJ, Huang CH, Hsieh WL, Wu HH. Analyzing emotional exhaustion from viewpoints of physicians and nurses - A case of a regional teaching hospital. TEM J. 2016;5(2):231235. doi:10.18421/TEM52-17.

18. Lee $\mathrm{YC}$, Huang $\mathrm{SC}$, Huang $\mathrm{CH}, \mathrm{Wu} \mathrm{HH}$. A new approach to identify high burnout medical staffs by kernel k-means cluster analysis in a regional teaching hospital in Taiwan. Inquiry. 2016;53. doi:10.1177/0046958016679306.

19. Kim J, An K, Kim MK, Yoon SH. Nurses' perception of error reporting and patient safety culture in Korea. West J Nurs Res. 2007;29(7):827-844

20. Karagiannopoulos M, Anyfantis D, Kotsiantis SB, Pintelas PE. Feature selection for regression problems. Proceedings of the 8th Hellenic European Research on Computer Mathematics \& Its Applications (HERCMA '07); 2007:20-22.
21. Singer S, Meterko M, Baker L, Gaba D, Falwell A, Rosen A. Workforce perceptions of hospital safety culture: development and validation of the patient safety climate in healthcare organizations survey. Health Serv Res. 2007;42(5):1999-2021. doi:10.1111/j.1475-6773.2007.00706.x.

22. El-Jardali $F$, Dimassi $H$, Jamal $D$, Jaafar $M$, Hemadeh $N$. Predictors and outcomes of patient safety culture in hospitals. Health Serv Res. 2011;11:45. doi:10.1186/1472-6963-11-45.

23. Barling J, Loughlin C, Kelloway EK. Development and test of a model linking safety-specific transformational leadership and occupational safety. J Appl Psychol. 2002;87:488-496.

24. Clarke S, Ward K. The role of leader influence tactics and safety climate in engaging employees' safety participation. Soc Risk Anal. 2006;26(5):1175-1185. doi:10.1111/j.15396924.2006.00824.x

25. Khater WA, Akhu-Zaheya LM, Al-Mahasneh SI, Khater R. Nurses' perceptions of patient safety culture in Jordanian hospitals. Int Nurs Rev. 2015;62(1):82-91. doi:10.1111/ inr. 12155.

26. Gallego B, Westbrook MT, Dunn AG, Braithwaite J. Investigating patient safety culture across a system: multilevel modelling of differences associated with service types and staff demographics. Int J Qual Health Care. 2012;24(4):311-320. doi:10.1093/intqhe/mzs028. 